\title{
Speed Sensorless Sliding Mode Control of Induction Motor Using Simulink
}

\author{
K.Venkateswarlu' ${ }^{1}$, G.Sandeep ${ }^{2}$, N.Srinivas ${ }^{3}$, K. Damodara Reddy ${ }^{4}$, \\ A.Ramakrishna ${ }^{5}$ \\ 1, 2, 3, 4, 5 (Department of EEE, Vardhaman College of Engineering, India)
}

\begin{abstract}
AC motors in particular squirrel cage induction motor (SCIM) enjoy several inherent advantages like simplicity, reliability, robust, low cost and maintenance free. The operation of induction motors in the constant volts per hertz (V/f) mode has been known for many decades, and its principle is well understood. V/f control has displaced the dc motor to some extent, particularly in the lower $k W$ range, and the majority of variable speed drives in operation today are of this type. However for high dynamic performance industrial applications their control remains a challenging problem because they exhibit coupled nature of the stator and rotor flux and also significant nonlinearities. Sliding mode control is novel and quite different than the conventional field oriented or direct torques control (DTC) and optimizes the torque response. A new stator and rotor flux observer based on continuous sliding mode which allows Induction motor operation at low speeds is proposed in this project. This model is characterized in the stator reference frame and modeled using MATLAB/SIMULINK.
\end{abstract}

Keywords: Induction Motor, sliding mode controller, sliding surface

\section{Introduction}

Electrical motors play vital role in the development of industrial systems. The DC machine was the first practical machine to convert electrical power into mechanical power, and vice versa. Inherent operating characteristics, flexible performance and efficiency encouraged the use of DC motors in many types of industrial drive application. The later developments of the low cost AC motors have displaced the DC motor to some extent. Induction motors are relatively economical, rugged and reliable machines due to the absence of commutators and brushes. Therefore much attention is given to their control for various applications with different control requirements.

An induction machine, especially squirrel cage induction machine, has many advantages when compared with DC machine. However, because of its highly non-linear and coupled dynamic structure, an induction machine requires more complex control schemes than DC motors. Traditional open-loop control of the induction machine with variable frequency may provide a satisfactory solution under limited conditions. However, when high performance dynamic operation is required, these methods are unsatisfactory. Therefore, more sophisticated control methods are needed to make the performance of the induction motor comparable with DC motors.

\section{Sliding Mode Control}

Sensorless torque control of an induction motor drive essentially means torque control without any speed sensor. An incremental shaft-mounted speed encoder (usually an optical type) is required for close loop speed or position control in both vector and scalar-controlled drives. A speed signal is also required in indirect vector control in the whole speed range. And in indirect vector control for the low speed range, including the zero speed stat-up operation. A speed encoder is undesirable in a drive because it adds cost and reliability problems, besides the need for a shaft extension and mounting arrangement. It is possible to estimate the speed signal from machine terminal voltages and currents with the help of a DSP or intelligent controller. However, the estimation is normally complex and heavily dependent on machine parameters. Although Sensorless controlled drives are commercially available at this time, the parameter variation problem, particularly near zero speed, imposes a challenge in the accuracy of speed estimation.

A sliding mode control (SMC) with a variable control structure is basically an adaptive control that gives robust performance of a drive with parameter variation and load torque disturbance. The control is nonlinear and can be applied to a linear or nonlinear plant. In an SMM, as the name indicates, the drive response is forced to track or "slide" along a predetermined trajectory or "reference model" in a phase plane by a switching control algorithm, irrespective of the plant's parameter variation and load disturbance. The control is nonlinear and can be applied to a linear or nonlinear plant. 


\subsection{Control Principle}

An SMC is basically a variable structure control system (VSS) [5] where the structure or topology of the control intentionally varied to stabilize the control and make its response robust. Consider a simple secondorder undamped linear system, as shown in Figure 2.1. With variable plant gain K. It can easily be seen that system is unstable in either negative or positive feedback mode. However, by switching back and forth between the negative and positive feedback modes, the system cannot only be made stable, but its response can be made independent to the plant parameter K. Consider Figure 2.1 in negative feedback mode with switch 1 closed. We can write

$$
\mathrm{X}_{1}=\mathrm{R}-\mathrm{C}
$$

Where $\mathrm{X}_{1}=$ loop error

$$
\mathrm{R}-\mathrm{X}_{1}=\mathrm{C}
$$

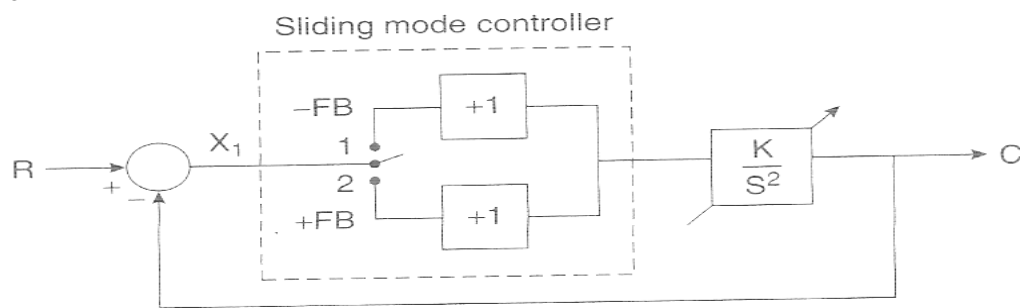

Figure 2.1 Variable structure control of second-order system

Differentiating equation (2.1)

$$
\begin{gathered}
\frac{\mathrm{d}}{\mathrm{dt}}\left(\mathrm{R}-\mathrm{X}_{1}\right)=\frac{\mathrm{dC}}{\mathrm{dt}}=-\mathrm{X}_{2} \\
\frac{\mathrm{dX} \mathrm{X}_{1}}{\mathrm{dt}}=\mathrm{X}_{2}
\end{gathered}
$$

Where $\mathrm{R}=$ step input with constant value at time $\mathrm{t}^{+}$and $-\mathrm{X}_{2}=\mathrm{dc} / \mathrm{dt}$. We can also write the derivative of $\mathrm{X}_{2}$ in the following form to satisfy the loop relation

Combining Equations (2.4) and (2.5)

$$
\frac{\mathrm{dX}_{2}}{\mathrm{dt}}=-\mathrm{KX}_{1}
$$

$$
\frac{\mathrm{d}^{2} \mathrm{X}_{1}}{d \mathrm{t}^{2}}+\mathrm{KX}_{1}=0
$$

This gives the second-order system model in terms of the loop error $X_{1}$ and its derivative $X_{2}$. The general solution of under damped equation, (2.6) is

$$
\begin{array}{r}
\mathrm{X}_{1}=A \sin (\sqrt{\mathrm{K}} \mathrm{t}+\theta) \\
\mathrm{X}_{2}=\frac{d \mathrm{~N}_{1}}{\mathrm{dt}}=\sqrt{\mathrm{K} A \cos (\sqrt{\mathrm{K}} \mathrm{t}+\theta)}
\end{array}
$$

Where $\mathrm{A}$ and $\theta$ are arbitrary constants. Combining them, we get

$$
\frac{x_{1}^{2}}{A^{2}}+\frac{x_{2}^{2}}{(\sqrt{K} A)^{2}}=1
$$

Equation (2.9) describes an ellipse with semi-axes A and $\sqrt{ } \mathrm{kA}$. Its phase plane trajectory is plotted in fig 2.1, which shows concentric ellipse with arbitrary A. the shape of the ellipse will vary with a variation of gain $\mathrm{K}$. In the positive feedback mode (switch 2 close) of fig 2.1 we can write the following equations:

$$
\begin{aligned}
& \frac{d X_{1}}{d t}=X_{2} \\
& \frac{d X_{2}}{d t}=K X_{1}
\end{aligned}
$$

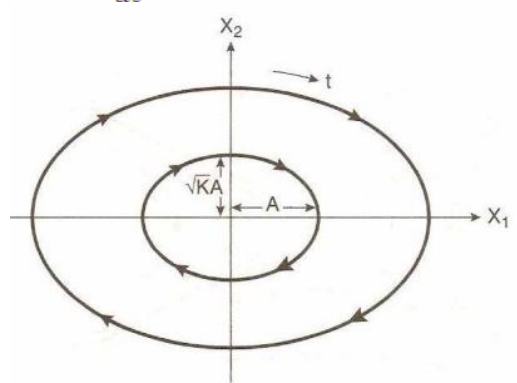

Figure 2.2 phase plane portrait of Figure 2.1 with negative feedback

Combining these equations, 


$$
\frac{d^{2} X_{1}}{d t^{2}}-K X_{1}=0
$$

The general solution of equation (3.12) is

$$
\begin{aligned}
& X_{1}=B_{1} e^{\sqrt{K} t}+B_{2} e^{-\sqrt{K} t} \\
& X_{2}=\frac{d x_{1}}{d t}=\sqrt{K}\left(B_{1} e^{\sqrt{K} t}-B_{2} e^{-\sqrt{K} t}\right)
\end{aligned}
$$

Where B1, B2 are arbitrary constants. Squaring each equation and combing them gives us

$$
\frac{X_{1}^{2}}{4 B_{1} B_{2}}-\frac{X_{2}^{2}}{4 K B_{1} B_{2}}=1
$$

Where B1, B2 term can be positive, negative or zero. Equation (2.15) describes hyperbolas that are plotted in the plane of figure 2.3. The straight line asymptote equations can be derived by substituting as

$$
\begin{aligned}
& K X_{1}^{2}-X_{2}^{2}=4 K B_{1} B_{2}=0 \\
& \text { i.e, } \quad X_{2}= \pm \sqrt{K} X_{1}
\end{aligned}
$$

The families of hyperbolas are plotted for B1 B2 > 0and B1 B2 $<0$. The system can be switched back and forth between the positive and negative feedback modes for SMC, as explained in Figure 2.4. The operation in Figure 2.4 can be understood by the superposition of Figure 2.2 and 2.3, where the hyperbolic asymptote line is described by the equation $\quad \sigma=\sqrt{K} X_{1}+X_{2}=0$

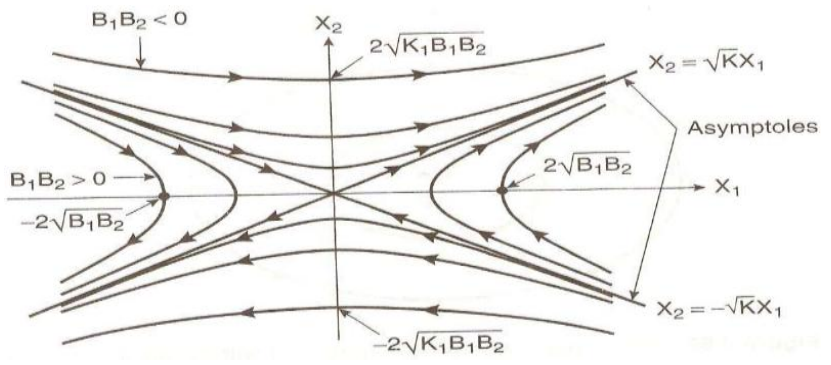

Figure 2.3 phase plane portrait of Figure 2.1 with positive feedback

Where $\sigma=0$ is the line. Assume that initially, the system is in negative feedback mode and the operation point is at $\mathrm{X}_{1}=\mathrm{X}_{10}$ on the ellipse. As the operating point moves on elliptic trajectory and touches point $\mathrm{B}$ as shown, in the positive mode is invoked. Ideally, it will then moves along the straight line BO and settle at steady-state point $\mathrm{O}$, where $\mathrm{X}_{1}$ and error velocity are zero. The slope of line $\mathrm{BO}$ may vary with variation of $\mathrm{K}$. even with constant $\mathrm{K}$, precision switching at point $\mathrm{B}$ is practically impossible to reach the steady-state point $\mathrm{O}$. let us define the sliding line equation as

$$
\sigma=c X_{1}+X_{2}=0
$$

Where $\mathrm{C}<\mathrm{K}^{0.5}$ so that the line slope is lower and beyond the range of the $\mathrm{K}$ variation. Note carefully that on the sliding line, defined as the "reference trajectory." Describe by hyperbolas and ellipses, respectively, cross in opposite directions. This means that at point B, the control can be switched to positive feedback mode, and then at point $\mathrm{D}$, it can be switched back to negative feedback mode, and so on. The operating point will thus track the sliding line in a zigzag path until the steady-state point is reached at the origin. The time-domain solution of the sliding line is basically a deceleration with exponentially decaying, as indicated by the following equation

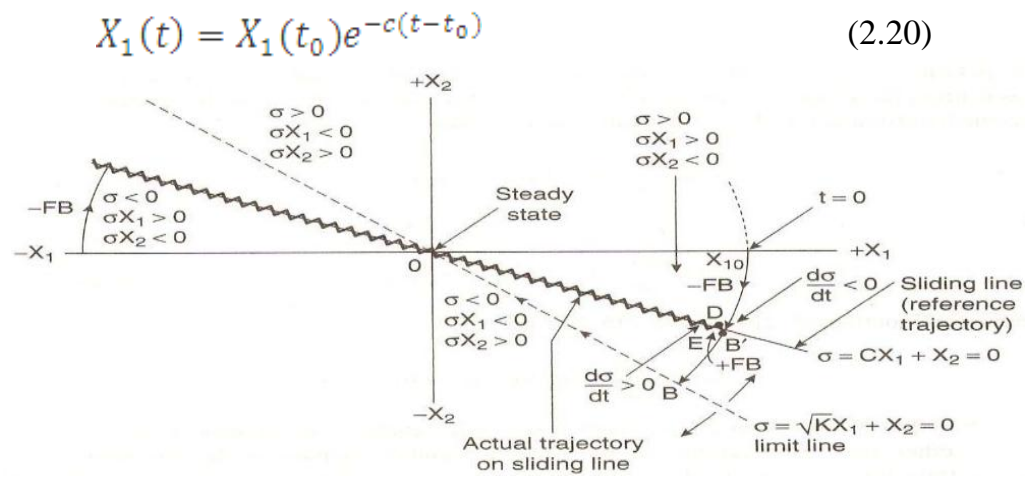

Figure2.4 Sliding line control in phase plane 
Where $\mathrm{t}_{0}=$ time at which the trajectory reaches the sliding line. The time-domain response for the sliding line control of two different values of $\mathrm{C}$ is shown in Figure 3.6, which reflects the characteristic chattering effect. None that once the operation reaches the sliding line, the response is strictly dictated by slope $\mathrm{C}$, but it is not affected by a variation of parameter $\mathrm{K}$ or any load disturbance (robust). The operation of the sliding line control in the second quadrant for $-\mathrm{X}-1$ (reverse position error) is similar to that for the fourth quadrant, and is shown in Figure 2.4. The polarities of parameters $\sigma, \sigma \mathrm{X}_{1}$, and $\sigma \mathrm{X}_{2}$ above and below the sliding line for both $+X_{1}$ and $-X_{1}$ are summarized in Figure 2.4. The strategy of switching control is defined by

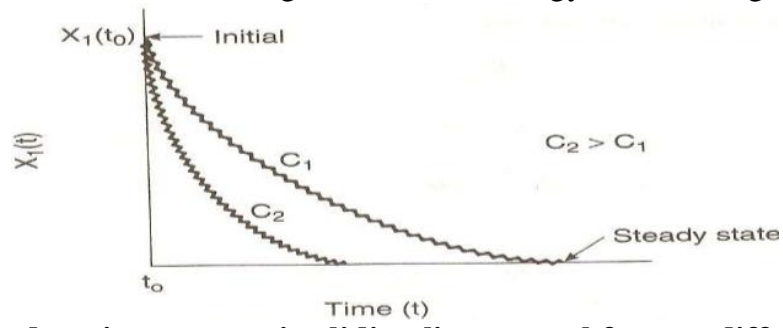

Figure 2.5 Time-domain response in sliding line control for two different values of $\mathrm{C}$

These polarities, which will be described later. Evidently, $\sigma>0$ and $\mathrm{d} \sigma / \mathrm{dt}<0$, as the trajectory trend to cross the sliding lines from above, where as $\sigma<0$ and $\mathrm{d} \sigma / \mathrm{dt}<0$, as the trajectory tends to cross the line from below. Mathematically, we can write

$$
\begin{aligned}
& \operatorname{Lim} \frac{d \sigma}{d t}<0 \text { for } \sigma \rightarrow+0 \\
& \operatorname{Lim} \frac{d \sigma}{d t}>0 \text { for } \sigma \rightarrow-0
\end{aligned}
$$

Combining equations (2.20) and(2.21), we get

$$
\operatorname{Lim} \frac{d \sigma}{d t}<0 \text { for } \sigma \rightarrow+0
$$

Equation (2.23) is defined as an existence or reaching equation, which must be satisfied for the SMC. In other words, the validity of the reaching equation guarantees that the response will cross the trajectory in each switching transition, and is essentially for a system to be controllable by the sliding mode. In practice, the parameters in the sliding mode controller are designed with the reaching equation.

\section{Simulation Of Various Models}

Machine dynamics and problem statement are discussed in the first part of this chapter. Then later part of the chapter focuses on the discussion about sliding-mode control system. Simulink models are developed for the various control circuits based on the equations given for stator flux sliding mode control, sliding mode flux observer.

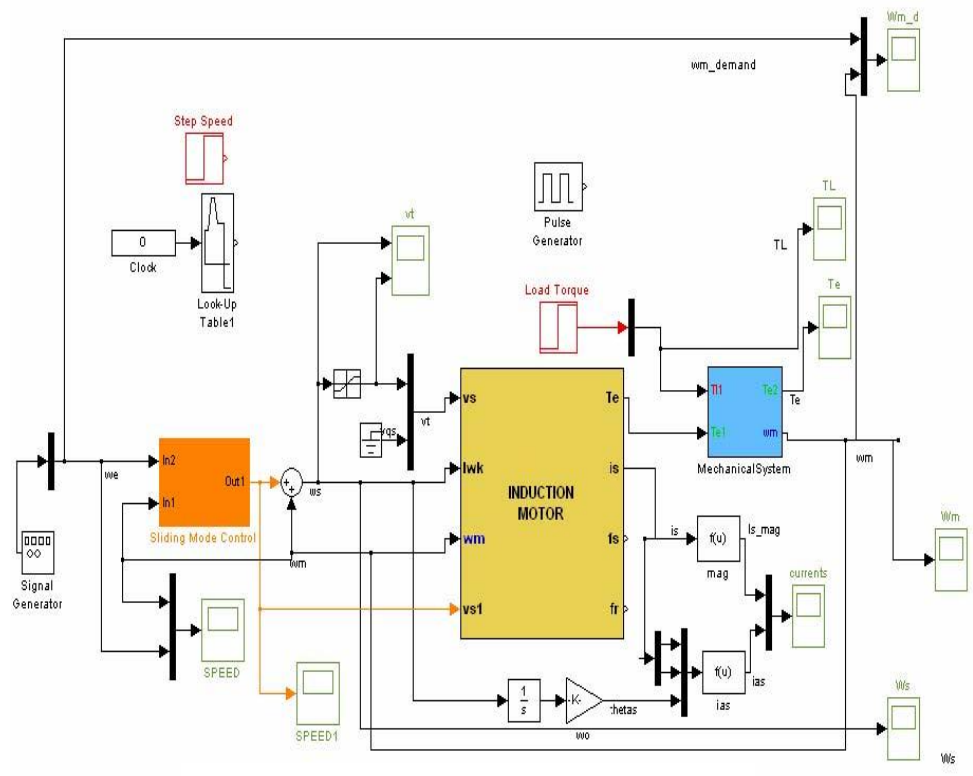

Figure 3.1 Simulink model for closed loop control scheme 


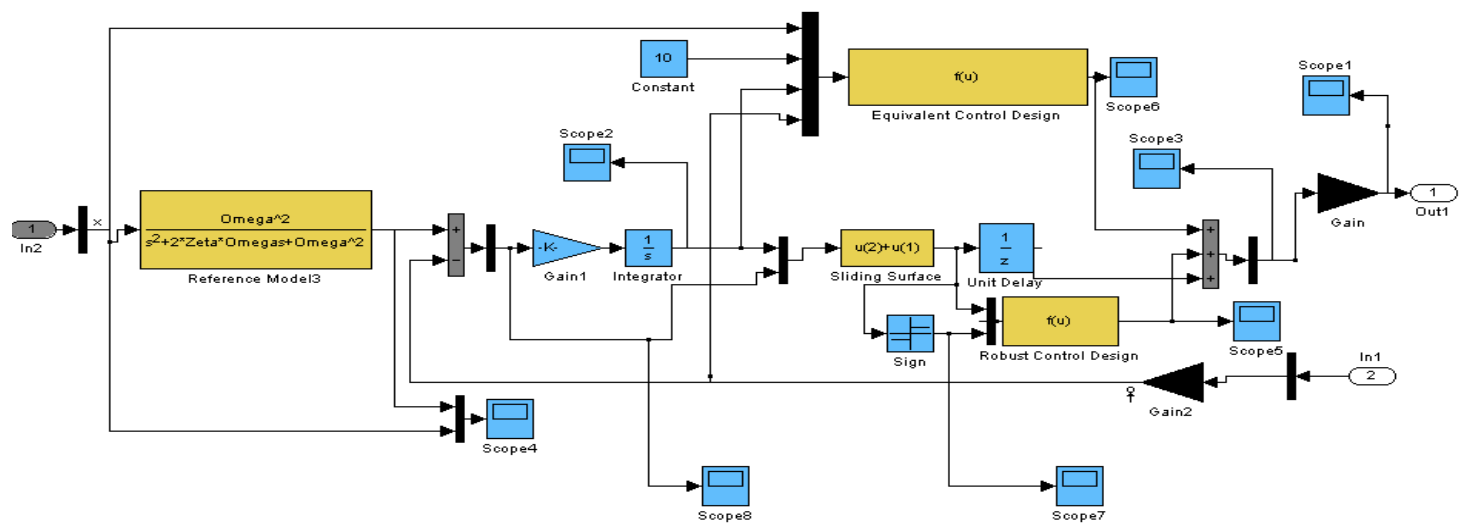

Figure 3.2 Simulink model for Sliding mode control scheme with closed loop

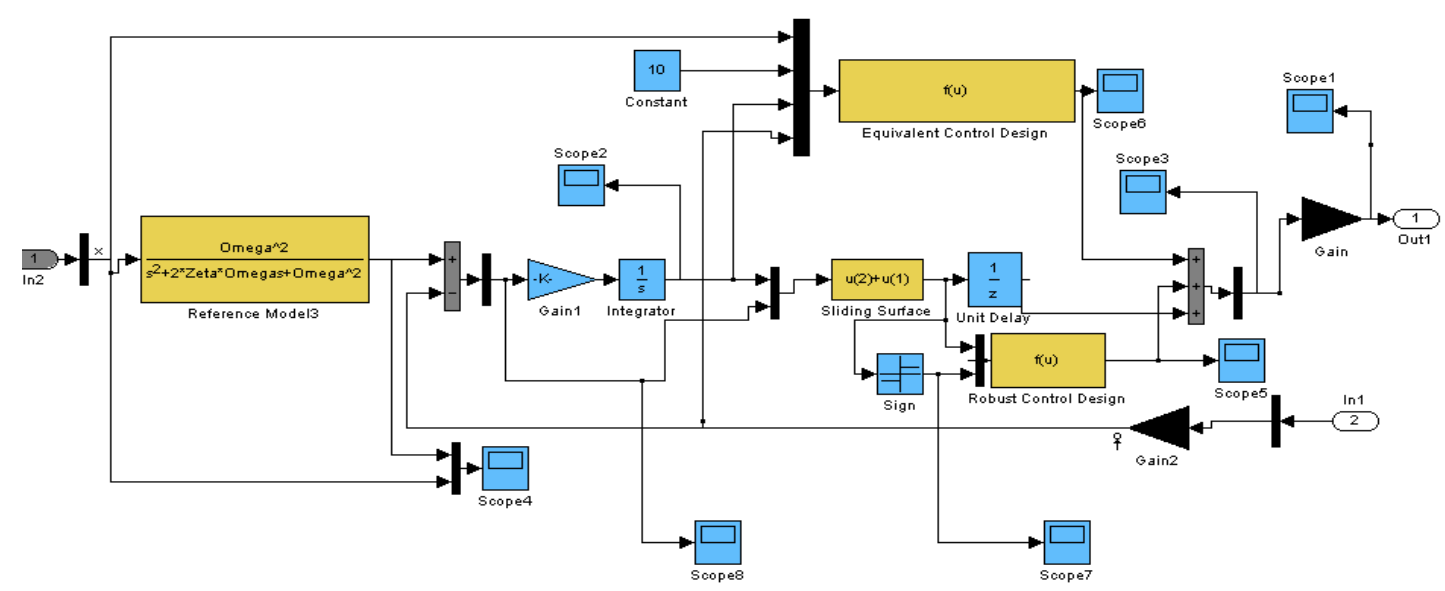

Figure 3.3 Simulink model for Induction Motor

\section{Simulation Results}

This control scheme of IM drive is simulated using Simulink. The IM used in simulation is Y connected 50 $\mathrm{Hz}, 4$ pole, $1500 \mathrm{rpm}$. Parameters in the per phase steady state equivalent circuits are (per unit values): stator resistance $\mathrm{Rs}=0.025$, rotor resistance $\mathrm{Rr}=0.015$, stator and rotor inductance $\mathrm{Ls} 1=\mathrm{Lr} 1=0.10$, mutual inductance $\mathrm{Lm}=3.0$, motor and load inertia $\mathrm{j}=0.239$.

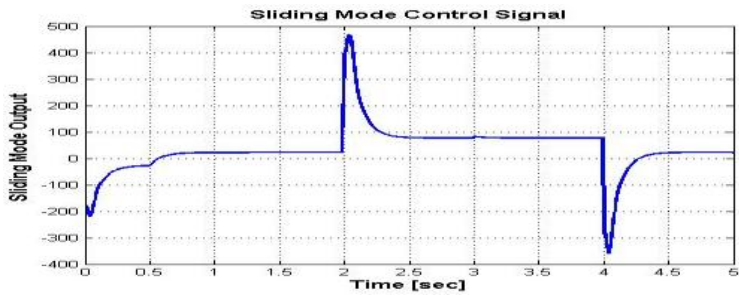

Figure 4.1 Sliding Mode control signal Figure

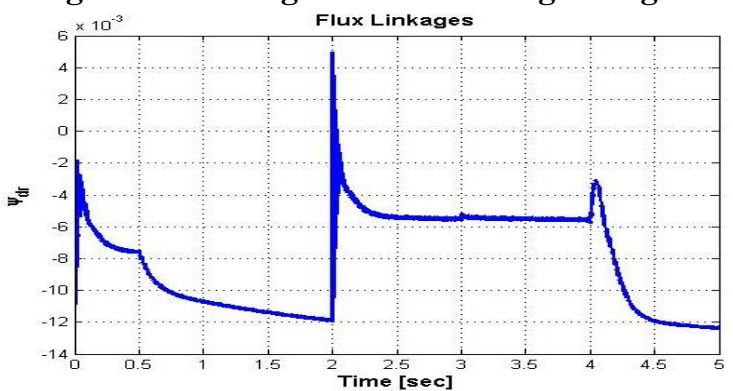

Figure 4.3 flux linkages $\psi q \mathrm{q}$

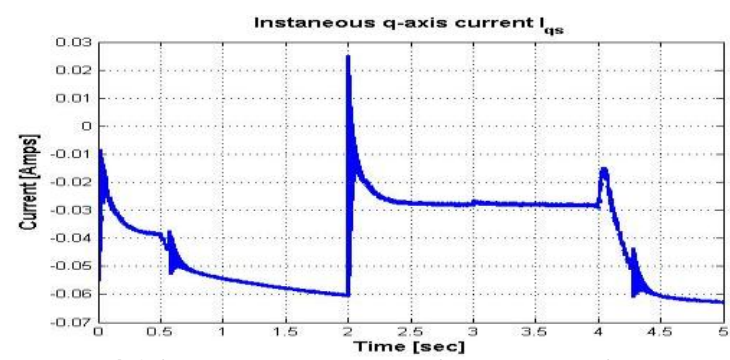

4.2 instantaneous q-axis currents iqs

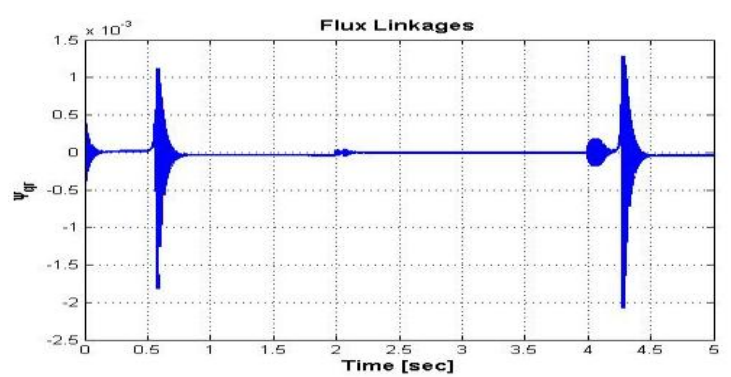

Figure 4.4 flux linkages $\psi q r$ 


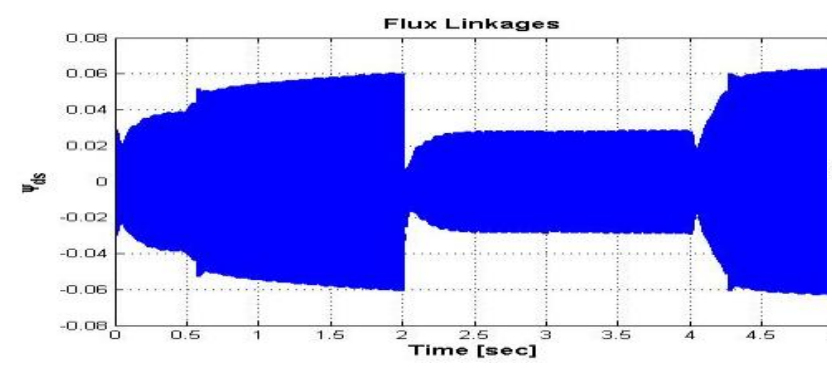

Figure 4.5 flux linkages $\psi q \mathrm{q}$

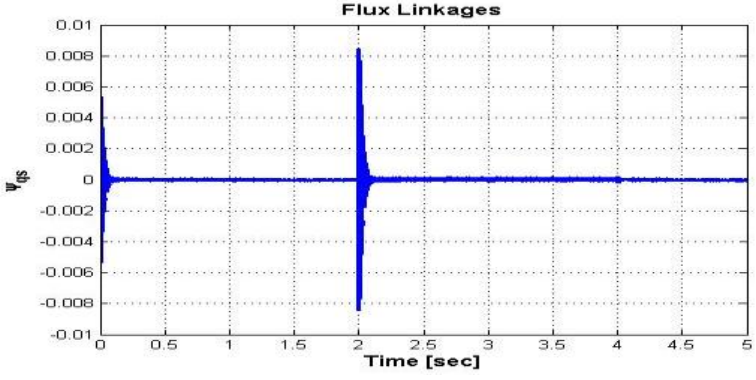

Figure 4.6 flux linkages $\psi d \mathrm{ds}$

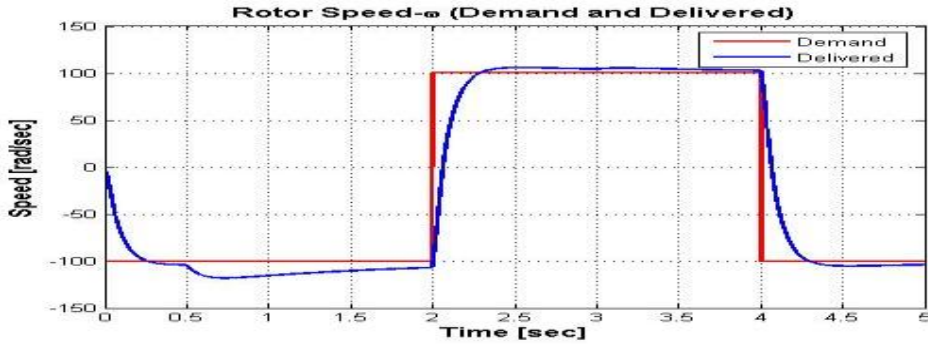

Figure 4.7 Rotor speed odemand, odelivered

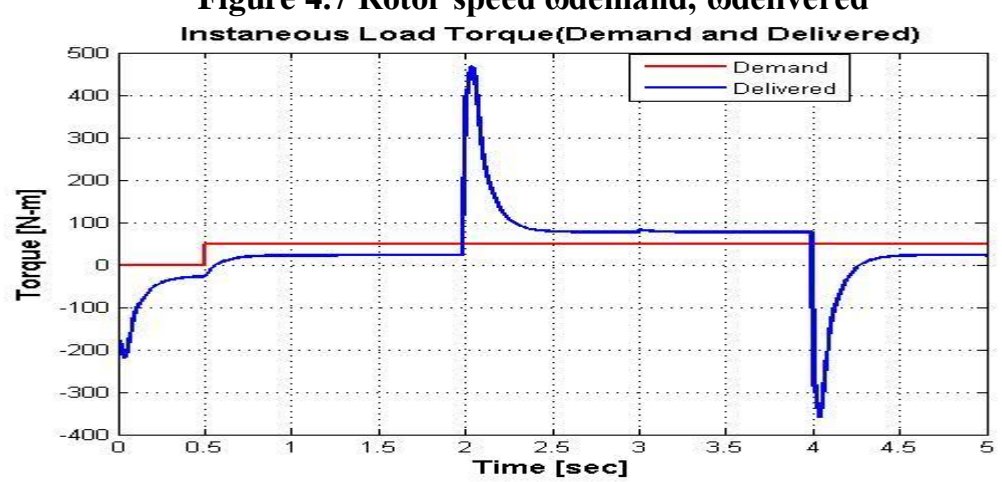

Figure 4.8 Instantaneous Load Torque and Demand Torque

\section{Conclusion}

The robust sliding mode control is presented in the stator fixed reference frame so that an easy description for a real-time operation could be found. Combining VSDS and Lyapunov design has developed a new discrete time control algorithm. It possesses all the good properties of the Sliding mode and eliminates the undesired chattering of control input. Sliding Mode Control has low speed tracking error and high control effort when compared to PI controller. In this paper, a speed Sensorless sliding mode control for IM is simulated using Matlab/simulink. The conclusion can be drawn from the results obtained in the previous chapter. New rotor flux observer allows the speed Sensorless operation of IM at low speeds. The same was shown in the graphs drawn in the figure 4.7. It is simple control method and quite different from the FOC and DTC.

\section{References}

[1] K.M.H. Kubota and T.Nakano, "DSP-based speed adaptive flux observer of induction Motor", IEEE Trans. Ind. Appl. vol.29, 1993 pp. 344-348.

[2] Hasan Zidan, Shuishi Fujji, Tsuyoshi Hanamoto, Reruo Tsujji "A simple Sensor-less vector Control System for Variable Speed Induction Motor Drives" paper conference.

[3] H. Tajima and Y. Hori. Speed sensorless field-orientation control of the induction Machine. IEEE Trans. Indust.Appl., 29(1):175-180, Jan/Feb 1993.

[4] Marcello montanaria, Sergei Peresadab, Andhrea Tillia, Alberto Toniellia "Speed Sensorless control of Induction Motor based on Indirect Field-Orientation".

[5] Karel Jezerink "Speed sensorless Torque control of induction Motor," University of Maribor, Faculty of Electrical Engineering and Computer Science.

[6] P.Vas, "Sensorless vector and direct torque control" Oxford University Press,1998

[7] Vadim I. Utkin 'Sliding Mode Cotrol Design Principles and Applications to Electric Drives", IEEE Trans on Industrial Electronics, VOL 40, NO.1. feb 1993 Tutorial Course, 1986.

[8] J.R.Zhang, S.J.Xu, and A.Rachid "Sliding Mode Controller for Automatic Path Tracking of Vehicles", Proceeding of the American Control Conference, Anchorage, AK May 8-10,2002. 
[9] Rong-Jong Wai, Kuo-Min Lin, and Chung-You Lin, " Total Sliding-mode Control of Field-Oriented Induction Motor Servo Drive".

[10] Abdelkrim Benchaib, Ahmed Rachi, Audrezet, and Mohamed Tadjine "Real-Time Sliding-Mode Observer and Control of an Induction Motor" IEEE Trans on Industrial Electronics, vol 46, no.1, feb 1999.

[11] Abdelkrim Benchaib, Ahmed Rachid, and Eric Audrezet, " Sliding-Mode Input-Output Linearization and Field Orientation for RealTime Control of Induction Motors", IEEE Trans on power Electronics, vol 14, no.1, jan 1999.

[12] EDWARD Y Y.HO,AND PARESH C. SEN,"Decoupling Control of Induction Motor Drives" IEEE Trans on Industrial Electronics, vol 35, no.2, MAY 1988. 